\title{
Continuous production of nanostructured particles using spatial atomic layer deposition
}

\author{
J. Ruud van Ommen, ${ }^{\text {a) }}$ Dirkjan Kooijman, Mark de Niet, Mojgan Talebi, \\ and Aristeidis Goulas \\ Department of Chemical Engineering, Delft University of Technology, Julianalaan 136, 2628 BL Delft, \\ The Netherlands
}

(Received 21 September 2014; accepted 29 December 2014; published 13 January 2015)

\begin{abstract}
In this paper, the authors demonstrate a novel spatial atomic layer deposition (ALD) process based on pneumatic transport of nanoparticle agglomerates. Nanoclusters of platinum (Pt) of $\sim 1 \mathrm{~nm}$ diameter are deposited onto titania $\left(\mathrm{TiO}_{2}\right) \mathrm{P} 25$ nanoparticles resulting to a continuous production of an active photocatalyst $(0.12-0.31 \mathrm{wt} . \%$ of $\mathrm{Pt})$ at a rate of about $1 \mathrm{~g} \mathrm{~min}^{-1}$. Tuning the precursor injection velocity $\left(10-40 \mathrm{~m} \mathrm{~s}^{-1}\right)$ enhances the contact between the precursor and the pneumatically transported support flows. Decreasing the chemisorption temperature (from 250 to $100{ }^{\circ} \mathrm{C}$ ) results in more uniform distribution of the Pt nanoclusters as it decreases the reaction rate as compared to the rate of diffusion into the nanoparticle agglomerates. Utilizing this photocatalyst in the oxidation reaction of Acid Blue 9 showed a factor of five increase of the photocatalytic activity compared to the native P25 nanoparticles. The use of spatial particle ALD can be further expanded to deposition of nanoclusters on porous, micron-sized particles and to the production of core-shell nanoparticles enabling the robust and scalable manufacturing of nanostructured powders for catalysis and other applications. (C) 2015 American Vacuum Society. [http://dx.doi.org/10.1116/1.4905725]
\end{abstract}

\section{INTRODUCTION}

Atomic layer deposition (ALD) is a coating technique relying on the distinct, consecutive binding of two or more compounds in a combined structure under a self-limiting chemisorption/reaction scheme. It can be used to deposit a wide range of materials. ${ }^{1}$ Whereas most ALD research is aimed at ultrathin film deposition on wafers and other flat substrates, depositing materials on nanoparticles and micronsized particles is also being investigated. ${ }^{2-7}$ This is of interest for a range of particulate materials with applications in Li-ion batteries, pigments, and catalysis. ${ }^{8,9}$ These applications require large amounts of materials, and it would be attractive to have a continuous process scheme in addition to the typically applied batchwise operation.

The majority of ALD research focuses at depositing continuous films, but in the first cycles submonolayer deposition can lead to incomplete surface coverage. Deposition of metals with high surface free energy, such as $\mathrm{Pt}$, on oxide supports, such as $\mathrm{TiO}_{2}$, has a strong tendency to proceed via island growth (Volmer-Weber mechanism). ${ }^{10}$ Ultimately, after a sufficient number of exposure cycles, the deposited islands will merge to form a thin film. However, for applications in catalysis, it is typically undesirable to obtain a continuous film: the island structure should be maintained to maximize the dispersion. ${ }^{11-13}$

For most practical catalytic applications, particles are used as support material. The deposition of materials on a particulate support via ALD was already proposed in the 1960 s in the former Soviet Union. ${ }^{14}$ In 1979, Yakovlev et al. $^{15}$ described the deposition of vanadium oxide on silica gel using ALD in a fluidized bed reactor. A fluidized bed is an amount of particles suspended in an upward gas flow. In

${ }^{a)}$ Electronic mail: j.r.vanommen@tudelft.nl the late $1980 \mathrm{~s}$, Asakura et al. ${ }^{16}$ used an approach similar to ALD to deposit 1-3 atomic layers of zirconia on zeolites, fabricating a catalyst for the conversion of methanol to isopentane. The preparation of an active nickel catalyst for toluene hydrogenation was soon after reported. ${ }^{17,18}$ To our knowledge, the first fabrication of a supported catalyst by ALD in a fluidized bed reactor was the ruthenium-bipyridine system used for 1-hexene hydroformylation and water-gas shift reaction. ${ }^{19}$ Fluidized bed ALD reactors are efficient reactor modules that can facilitate scaled-up production of nanostructured powders on the kg scale. ${ }^{20}$

ALD is an attractive technique especially for the deposition of noble metals, since it can deposit the catalytic sites in a tailored manner: a controlled particle diameter with a small standard deviation can be obtained. Moreover, with ALD a high metal precursor usage efficiency can be realized, which is attractive when working with scarce, expensive metals. ${ }^{21}$ Finally, it is relatively easy to make bimetallic particles for catalysis with ALD. ${ }^{22}$

Most ALD reactors are operated in a temporal manner: the pulses of the different reactant gases are delivered subsequently in time. An alternative is to separate administration of the reactants in space. Spatial ALD was already described in the early patent of Suntola and Antson. ${ }^{23}$ In spatial ALD, either the substrate or the reactant injection points are moved such that the substrate surface area is alternately exposed to different reaction zones. The use of spatial ALD schemes implemented in inline deposition systems is expected to be inevitable when extremely high throughputs are required at low cost. In these cases, ALD processes are preferably operated at atmospheric pressure, enabling gas barriers to separate the reaction zones and avoiding the need for expensive vacuum equipment. ${ }^{24}$

Levy et al. ${ }^{25}$ demonstrated the deposition of alumina on thin film transistors in an open-air ALD deposition system. 
They envisioned that this deposition system will be adaptable to very large format, continuous, high-throughput processing and they explored several designs for the coating head, ${ }^{26}$ which was found to be one of the main challenges in continuous ALD. ${ }^{24}$ Poodt et al. ${ }^{27}$ reported the deposition of alumina using a spatial ALD reactor concept where the substrate is a rotating disk. In their design, the reaction zones are separated by gas bearings. For coating flexible substrates, such as organic light-emitting diodes, organic photovoltaic cells, and high-performance packing foils, spatial ALD is very attractive. Most concepts are based on keeping the precursor gases in confined volumes and passing the substrate through these volumes to achieve the required successive precursor doses. ${ }^{24,28-31}$

Envisioned applications of nanostructured particles prepared by ALD, such as catalysis and energy storage, typically require large amounts of materials. Therefore, it is desirable to develop a spatial ALD process for particles too. In temporal processing, the particles are typically suspended, either in a gas flow or by rotation to warrant good contact between the gaseous reactants and the particle surface., ${ }^{3,6,7}$ By conveying particles with a gas flow, we can obtain such a suspension while simultaneously using this flow to move the particles from the one reaction zone to the other. In fact, pneumatic transport of particles is widely used in industry, albeit mostly for micron-sized particles. ${ }^{32}$

Nanoparticles can be transported by a gas flow as aerosols: particles with a large enough interparticle distance to avoid serious agglomeration. ${ }^{33}$ However, this would require a very low particle mass fraction, which would make it impossible to reach the goal of high-throughput production. The alternative is to accept agglomeration, and to process nanoparticle agglomerates instead of single nanoparticles. It has been demonstrated that batch-wise ALD on nanoparticles works very well in a fluidized bed. ${ }^{3,13}$ During fluidization, the nanoparticles form agglomerates with a very open, fractal nature enabling a good access of precursors to the surface. ${ }^{34-36}$ In temporal ALD, this has led to a very good dispersion of deposited material over the particles.

The objective of this paper is to give a proof of principle: we demonstrate spatial ALD on pneumatically transported titania $\left(\mathrm{TiO}_{2}\right)$ nanoparticles. By depositing platinum $(\mathrm{Pt})$ nanoclusters on the nanoparticles that are transported by a nitrogen $\left(\mathrm{N}_{2}\right)$ flow, we obtain the continuous production of an active photocatalyst at a rate of about $1 \mathrm{~g} \mathrm{~min}^{-1}$. The $\mathrm{TiO}_{2}$ particles contain $0.12-0.31 \mathrm{wt}$. \% of $\mathrm{Pt}$ in nanoclusters of $\sim 1 \mathrm{~nm}$ diameter. Reaction tests show a factor of five increase of the photocatalytic activity compared to the native nanoparticles.

\section{EXPERIMENT}

We use a $27 \mathrm{~m}$ long, $4 \mathrm{~mm}$ internal diameter tube as our ALD reactor. The substrate nanoparticles $\left(\mathrm{TiO}_{2} \mathrm{P} 25\right)$ are fed at about $1 \mathrm{~g} \mathrm{~min}^{-1}$ into this tube from a vessel in which they are suspended in an upward $\mathrm{N}_{2}$ flow, a so-called fluidized bed. They are pneumatically transported through the tube with a $\mathrm{N}_{2}$ flow at a velocity of $5 \mathrm{~m} \mathrm{~s}^{-1}$ at the entrance.

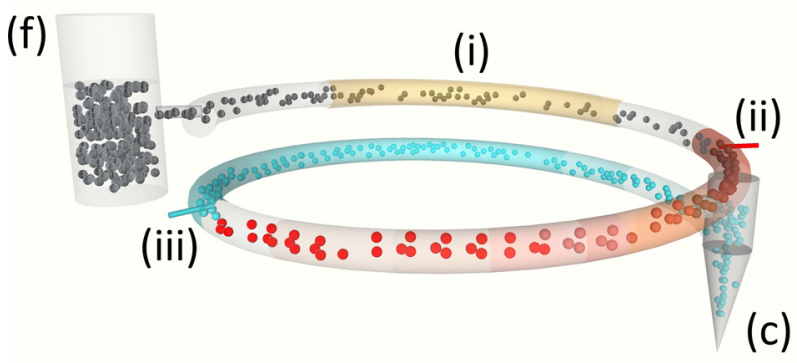

FIG. 1. (Color online) Schematic of the spatial ALD reactor consisting of a fluidized feeding vessel (f), a pneumatic transport line made of three segments: preheating (i), precursor reaction zone (ii), co-reactant reaction zone (iii), and a collection vessel (c).

In this study, we operate the system at atmospheric pressure, since we obtained good results with Pt ALD at atmospheric pressure before. ${ }^{13}$ However, vacuum conveying would also be possible. ${ }^{37}$ Operation under vacuum conditions is often preferred to facilitate a higher concentration of the precursors under the selected vaporization temperature conditions. The pneumatic transport line consists of three segments (Fig. 1): (i) the heating section; (ii) the reaction section A for the first half-reaction; this section starts with the injection of the Pt-precursor, $\mathrm{MeCpPtMe}_{3}$; and (iii) the reaction section $\mathrm{B}$ for the second half-reaction; this section starts with the injection of air to provide the co-reactant (oxidizer), oxygen $\left(\mathrm{O}_{2}\right)$.

We work with a relatively dense nanoparticle flow. The particle flow is monitored by measuring the pressure drop in the reactor tube using differential pressure indicators. To supply our pneumatic reactor with the substrate nanoparticles, we use a $20 \mathrm{~cm}$ diameter fluidized bed column as a feeding vessel. This column contains Aeroxide P25 titanium dioxide nanoparticles $\left(\sim 500 \mathrm{~g}, \mathrm{TiO}_{2}, \geq 99.5 \%\right.$ purity) from Evonik Industries. Their average primary particle diameter is $21 \mathrm{~nm}$, and their specific surface area is $50 \mathrm{~m}^{2} \mathrm{~g}^{-1}$. Before loading them in the vessel, these particles are dried in an oven at $105^{\circ} \mathrm{C}$ for $24 \mathrm{~h}$. The bed is fluidized with $0.75 \mathrm{~cm} \mathrm{~s}^{-1}$ dry nitrogen $\left(\mathrm{N}_{2}, 99.999\right.$ vol. \%, from Linde) and vibrated at $35 \mathrm{~Hz}$ to ensure good fluidization. From the column, the particles are fed at a rate of about $1 \mathrm{~g} \mathrm{~min}^{-1}$ to a tube with an internal diameter of $4 \mathrm{~mm}$ and a length of $27 \mathrm{~m}$. They are initially transported with a $\mathrm{N}_{2}$ gas flow at a velocity of $5 \mathrm{~m} \mathrm{~s}^{-1}$. The first $7 \mathrm{~m}$ are used to preheat the particles to $100^{\circ} \mathrm{C}$. At $x=7 \mathrm{~m}$ (" $x$ " denoting the length of the reactor tube), $\mathrm{N}_{2}$ carrier gas containing the Pt precursor vapors, (trimethyl) methylcyclopentadienyl platinum(IV) ( $\mathrm{MeCpPtMe}_{3}$, 99\% purity, obtained from Strem Chemicals) is injected into the system (in order to control the precursor vapors in the carrier gas flow, the Pt bubbler was heated to 70 or $80^{\circ} \mathrm{C}$ ); this second part of the reactor is also kept at $100{ }^{\circ} \mathrm{C}$ to enable chemisorption of the precursor. ${ }^{38,39}$ At $x=17 \mathrm{~m}$, a $\mathrm{N}_{2}$ flow with 20.9 vol. $\% \mathrm{O}_{2}$ is injected into the tube. The temperature of this third part of the reactor is $220^{\circ} \mathrm{C}$. At $x=27 \mathrm{~m}$, the particles leave the reactor and flow into the bottom of the collection vessel. This is a vertical tube $(0.10 \mathrm{~m}$ diameter, 
$0.50 \mathrm{~m}$ height) with a filter on the top (pore diameter $20 \mu \mathrm{m}$ ), which is well able to capture the nanoparticle agglomerates.

In this proof of principle, we apply only one ALD cycle, but when multiple ALD cycles are required, this is just a matter of extending the tube and adding more injection points. The precursor is initially injected via tubes of $4 \mathrm{~mm}$ inner diameter. When it appears that this leads to too little mixing, the diameter of these tubes is reduced to $0.5 \mathrm{~mm}$ to increase the velocity and thus the mixing of the precursor flow.

To assess the mixing of the injected precursor, we carry out simulations with COMSOL MULTIPHYSICS 4.3a. Using the $\mathrm{k}-\varepsilon$ turbulence model, we perform single-phase simulations (i.e., no particles are taken into account). This is reasonable, since the nanoparticle agglomerates have both a low density and a low concentration in the gas flow. In the simulations, the injection tube is constant in diameter (i.e., the precursor volume flow rate is increased), while in practice, the diameter of the injection tube is decreased to increase the velocity of the precursor at equal volumetric flow rate. These steady state simulations are just meant to give qualitative indications of the flow behavior; we do not use the results as quantitative data.

The specific surface area of the nanopowders used was estimated by nitrogen adsorption in a Tristar II Micromeritics. The Pt content of the particles is measured by inductively coupled plasma optical emission spectroscopy in a Perkin Elmer Optima DV optical emission spectrometer. The dispersion/size of Pt clusters over the $\mathrm{TiO}_{2}$ nanoparticles is deducted by transmission electron microscopy (TEM, 200 kV FEI monochromated F20 UT Tecnai).

To use the $\mathrm{Pt} / \mathrm{TiO}_{2}$ particles in photocatalytic activity tests, they are first reduced in a packed bed column using a mixed flow of nitrogen and hydrogen, while heating the samples to $200^{\circ} \mathrm{C}$. The activity tests are carried out by dispersing a known amount of sample $(50 \mathrm{mg})$ in a $0.03 \mathrm{mM}$ solution of erioglaucine disodium salt (Acid Blue 9, $100 \mathrm{ml}$ ) containing 2 vol. \% of sodium polyphosphate to enhance the dispersion. After $10 \mathrm{~min}$ of sonication, the samples are irradiated with $330 \mathrm{~nm} \mathrm{UV}$ light $\left(3.5 \mathrm{~W} \mathrm{~m}^{-2}\right)$ under stirring at $30^{\circ} \mathrm{C}$. Samples are taken at fixed times, and after removing the particles by centrifugation, the concentration of Acid Blue 9 is determined with UV-Vis spectrometry $(630 \mathrm{~nm})$.

\section{RESULTS AND DISCUSSION}

In this proof of principle, we apply just one ALD cycle. Previously obtained results for batch-wise ALD in a fluidized bed reactor showed that one cycle would already give decent saturation Pt loading (up to 1 wt. \%) on $\mathrm{TiO}_{2}$ nanoparticles. ${ }^{13}$ However, when multiple ALD cycles are required, this is just a matter of extending the tube and adding more injection points. Since the reaction by-products are not expected to hamper the reaction, we do not purge between the two reaction sections.

Initial experiments yield a very uneven distribution of $\mathrm{Pt}$ over the $\mathrm{TiO}_{2}$ nanoparticles. Although elemental analysis indicates a reasonable $\mathrm{Pt}$ loading, $(0.57 \mathrm{wt}$. \%), images obtained by TEM show hardly any Pt clusters. Only after oxidation at $250^{\circ} \mathrm{C}$ for $16 \mathrm{~h}$, some of the Pt nanoclusters become visible [Fig. 2(a)], whereas a large part of the $\mathrm{TiO}_{2}$ hardly shows any Pt presence.

Suspecting an insufficient mixing of the precursor stream at the injection point, we use simulations of the gas flow to assess this in more detail. Figure 3(a) shows that the used precursor inlet velocity $\left(10 \mathrm{~m} \mathrm{~s}^{-1}\right)$ indeed leads to very poor mixing, allowing the Pt-precursor to react only with particles that pass close-by the inlet. Additional simulations show that increasing the inlet velocity to $40 \mathrm{~m} \mathrm{~s}^{-1}$ solves this problem: it enhances significantly contacting between the flows [Fig. 3(b)]. In practice, this is achieved by reducing the diameter of the injection tube.

TEM samples from subsequent experiments indeed show a better spread of the Pt nanoclusters, albeit still not
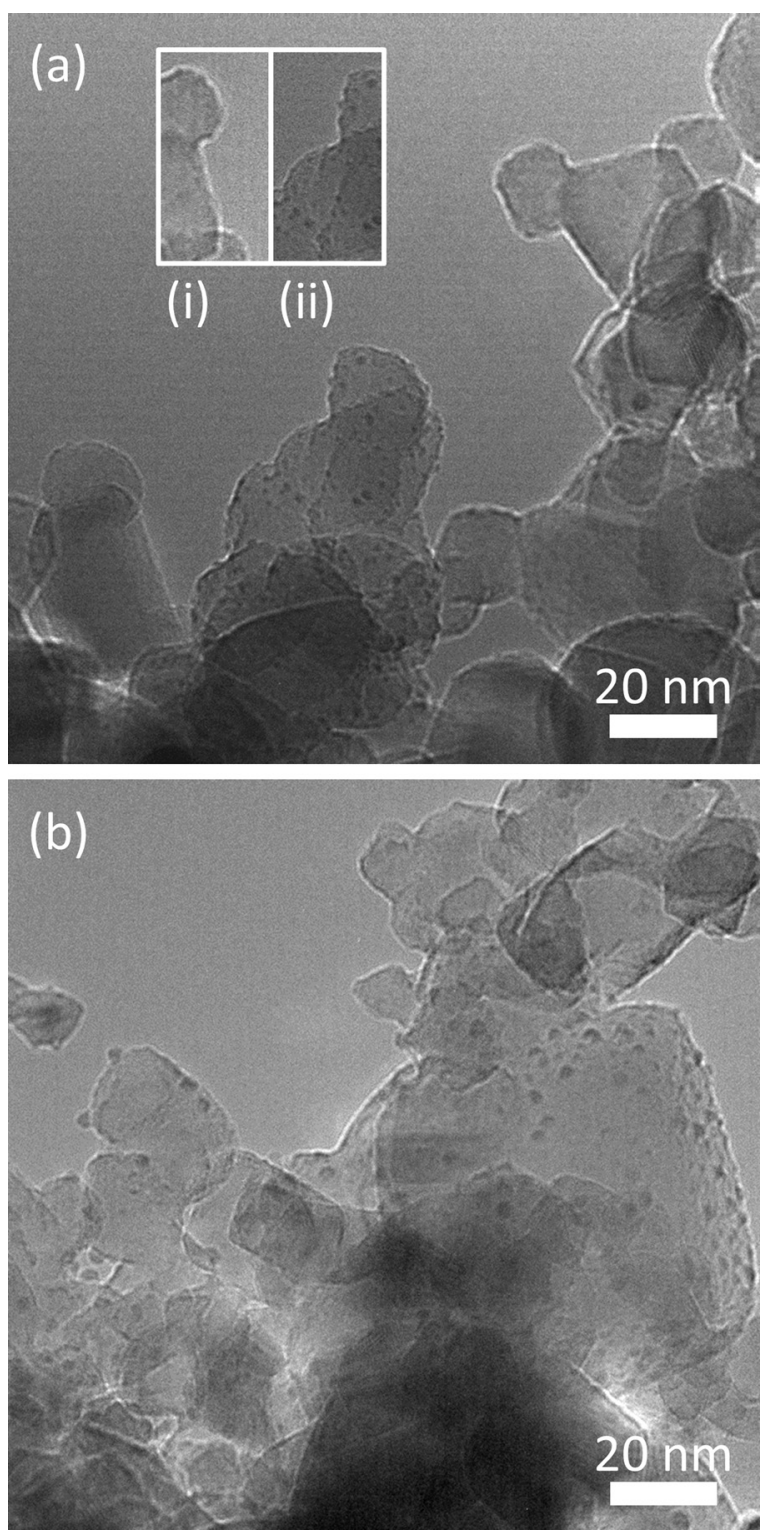

FIG. 2. TEM images of $\mathrm{Pt} / \mathrm{TiO}_{2}$ samples obtained by spatial ALD for (a) insufficient mixing $(0.57 \mathrm{wt} . \% \mathrm{Pt})$; the inset image illustrates the nonuniformity of deposition by comparing an uncoated (i) and a coated (ii) $\mathrm{TiO}_{2}$ particle. (b) Sufficient mixing that yields uniform coverage of the support particles (0.31 wt. \% Pt). 
(a) precursor inlet point

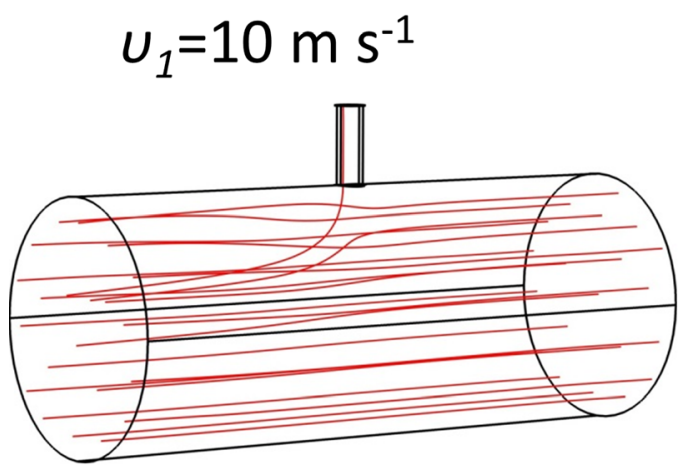

(b) precursor inlet point $u_{2}=40 \mathrm{~m} \mathrm{~s}^{-1}$

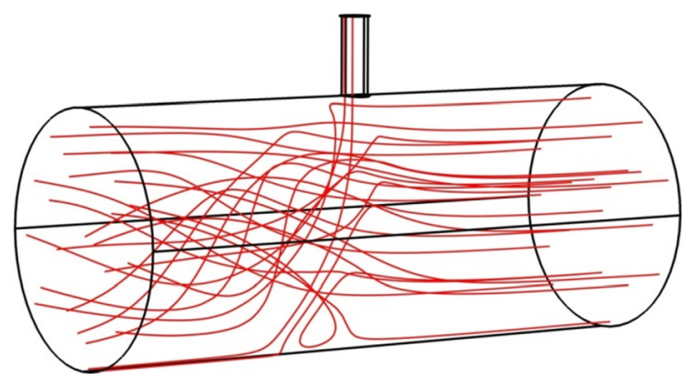

FIG. 3. (Color online) Stream line plots of the gas flow obtained with singlephase COMSOL simulations; the main gas flow is from right to left. (a) At an injection velocity $\left(v_{1}\right)$ of $10 \mathrm{~m} \mathrm{~s}^{-1}$, the mixing is insufficient. (b) At an injection velocity $\left(\mathrm{v}_{2}\right)$ of $40 \mathrm{~m} \mathrm{~s}^{-1}$ good mixing of the precursor flow with the main gas flow is obtained.

homogeneous. A second measure to increase the homogeneity is to decrease the temperature in reaction section A. This favors a more homogeneous distribution of the Pt precursor since the saturation value of the $\mathrm{TiO}_{2}$ nanoparticles decreases with decreasing temperature. ${ }^{40}$ Additionally, a lower temperature decreases the reaction rate as compared to the rate of diffusion into the nanoparticle agglomerates. By operating reaction section $\mathrm{A}$ at $100^{\circ} \mathrm{C}$, a homogeneous distribution of the $\mathrm{Pt}$ nanoclusters over the $\mathrm{TiO}_{2}$ particles is obtained, as shown by TEM images of samples taken directly from the reactor [i.e., without additional oxidation; Fig. 2(b)]. Under typical operating conditions, the wall surface area of the current reactor layout accounts for less than $10 \%$ of the total surface area involved. Scaling-up the reactor will favor precursor utilization, as this ratio will further decrease.

The function of reaction zone B is to complete the ALD cycle by oxidizing the organic ligands of the Pt precursor; we operate this section at $220^{\circ} \mathrm{C}$. To confirm the efficient removal of the ligands, we calcined one sample at $250{ }^{\circ} \mathrm{C}$ for $16 \mathrm{~h}$ in air. TEM did not indicate any changes compared to those taken before the $16 \mathrm{~h}$ heating. In addition, we found that it did not influence the catalytic activity, confirming that operating reaction section $\mathrm{B}$ at $220^{\circ} \mathrm{C}$ is sufficient to complete the oxidation. We are not saturating the

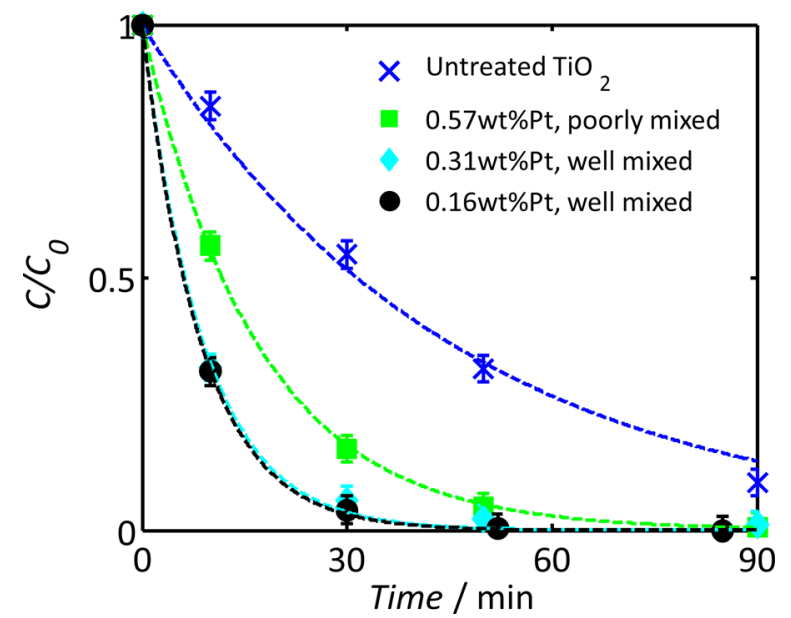

FIG. 4. (Color online) Normalized concentration of Acid Blue 9 as a function of time during the oxidation reaction on different photocatalyst samples. The dashed lines give a fit for a first-order reaction, from which the kinetic rate constants are determined (see Table I).

$\mathrm{TiO}_{2}$ particles surface with precursor in the first half-cycle: the loading can be varied by varying the ratio between nanoparticle feed flow and the precursor feed flow. We vary the particle flow between 0.8 and $2.9 \mathrm{~g} \mathrm{~min}^{-1}$, and the precursor feed flow between 0.1 and 0.5 standard liter per minute. In this way, we obtain Pt loadings between 0.12 and 0.31 wt. \% . The sizes of the Pt nanoclusters obtained by TEM are typically $1-2 \mathrm{~nm}$ for $0.31 \mathrm{wt}$. \% [Fig. 2(b)]. The tubular reactor used enables the control of separate temperatures for the A and B half-reactions, an approach that can enable low-temperature metal precursor exposure schemes. ${ }^{41}$

To assess the photocatalytic performance of the obtained material, we test it in the oxidation of Acid Blue 9. The samples are first reduced with hydrogen, and subsequently dispersed in a solution of Acid Blue 9 irradiated with $330 \mathrm{~nm}$ UV light. The reaction already runs with native $\mathrm{TiO}_{2} \mathrm{P} 25$, but a strong increase in the activity is obtained using our Ptdecorated $\mathrm{TiO}_{2}$ samples as illustrated in Fig. 4.

We test a sample obtained with insufficient mixing and three samples with a homogenous Pt distribution obtained by a properly mixed precursor flow. The poorly mixed and well-mixed samples showed comparable values of BET surface area of $52 \pm 3$ and $53 \pm 1 \mathrm{~m}^{2} / \mathrm{g}$, respectively (measured in a TriStar II Micromeritics). The first-order kinetic rate constant for particles with inhomogeneously distributed $\mathrm{Pt}$ is about 2.5 times higher than that of the untreated $\mathrm{TiO}_{2}$, while that of the evenly distributed $\mathrm{Pt}$ is up to 5 times higher, even though the Pt loading is considerably lower (Table I).

Zhou et al. ${ }^{40}$ studied the photocatalytic activity of $\mathrm{Pt} / \mathrm{TiO}_{2}$ nanoparticles prepared by ALD in a batch process. They observed an activity increase for the decomposition rate of Methylene Blue-a reaction similar to the one we used-with at maximum a factor of three, but they used a higher deposition temperature of $320^{\circ} \mathrm{C}$ while utilizing a loading of $0.64 \mathrm{wt}$. \% Pt to achieve this. 
TABLE I. Platinum fractions and first-order kinetic rate constants (incl. 95\% confidence interval) for samples used in the photocatalytic decomposition reaction of Acid Blue 9.

\begin{tabular}{lcc}
\hline \hline Sample & Pt fraction (wt. \%) & Kinetic rate constant $\left(\mathrm{s}^{-1}\right)$ \\
\hline Untreated $\mathrm{TiO}_{2}$ & 0.00 & $0.0221 \pm 0.0004$ \\
Poorly mixed & 0.57 & $0.0592 \pm 0.0012$ \\
Well-mixed 1 & 0.31 & $0.1107 \pm 0.0035$ \\
Well-mixed 2 & 0.16 & $0.1150 \pm 0.0031$ \\
Well-mixed 3 & 0.12 & $0.0820 \pm 0.0020$ \\
\hline \hline
\end{tabular}

\section{SUMMARY AND CONCLUSIONS}

We have demonstrated that with spatial particle ALD, it is possible to decorate the surface of ceramic nanoparticles with platinum nanoclusters, yielding a highly active photocatalyst. The efficient use of noble metals such as platinum has an impact far beyond photocatalysis. Many industrial catalyst applications rely on scarce and expensive noble metals. Methods to produce such catalysts with significantly lower noble-metal contents in a scalable manner are thus of key importance. Spatial particle ALD can further be extended to deposition of nanoclusters on porous, micron-sized particles, and to the production of core-shell nanoparticles. The latter case will require more injection points enabling multiple ALD cycles, which is deemed technically feasible.

\section{ACKNOWLEDGMENTS}

The research leading to these results has received funding from the European Research Council under the European Union's Seventh Framework Programme (FP/2007-2013)/ ERC Grant, Agreement No. 279632.

${ }^{1}$ V. Miikkulainen, M. Leskelä, M. Ritala, and R. L. Puurunen, J. Appl. Phys. 113, 021301 (2013).

${ }^{2}$ S. Haukka, E.-L. Lakomaa, and T. Suntola, Thin Solid Films 225, 280 (1993).

${ }^{3}$ J. R. Wank, S. M. George, and A. W. Weimer, Powder Technol. 142, 59 (2004).

${ }^{4}$ J. A. McCormick, B. L. Cloutier, A. W. Weimer, and S. M. George, J. Vac. Sci. Technol., A 25, 67 (2007).

${ }^{5}$ J. A. Libera, J. W. Elam, and M. J. Pellin, Thin Solid Films 516, 6158 (2008).

${ }^{6}$ R. Beetstra, U. Lafont, J. Nijenhuis, E. M. Kelder, and J. R. van Ommen, Chem. Vap. Deposition 15, 227 (2009).

${ }^{7}$ D. Longrie, D. Deduytsche, J. Haemers, K. Driesen, and C. Detavernier, Surf. Coat. Technol. 213, 183 (2012).
${ }^{8}$ C. Marichy, M. Bechelany, and N. Pinna, Adv. Mater. 24, 1017 (2012).

${ }^{9}$ X. Meng, X.-Q. Yang, and X. Sun, Adv. Mater. 24, 3589 (2012).

${ }^{10}$ L. Vitos, A. V. Ruban, H. L. Skriver, and J. Kollár, Surf. Sci. 411, 186 (1998).

${ }^{11}$ J. S. King et al., Nano Lett. 8, 2405 (2008).

${ }^{12}$ J. Li, X. Liang, D. M. King, Y.-B. Jiang, and A. W. Weimer, Appl. Catal., B 97, 220 (2010).

${ }^{13}$ A. Goulas and J. R. van Ommen, J. Mater. Chem. A 1, 4647 (2013).

${ }^{14}$ R. L. Puurunen, J. Appl. Phys. 97, 121301 (2005).

${ }^{15}$ S. V. Yakovlev, A. A. Malygin, S. I. Kol'tsov, V. B. Aleskovskii, Y. G. Chesnokov, and I. O. Protod'yakonov, J. Appl. Chem.-USSR 52, 959 (1979).

${ }^{16}$ K. Asakura, M. Aoki, and Y. Iwasawa, Catal. Lett. 1, 395 (1988).

${ }^{17}$ L. P. Lindfors and T. Salmi, Ind. Eng. Chem. Res. 32, 34 (1993).

${ }^{18}$ M. Lindblad, L. P. Lindfors, and T. Suntola, Catal. Lett. 27, 323 (1994).

${ }^{19}$ P. Hirva, T. Venäläinen, and T. A. Pakkanen, J. Catal. 148, 722 (1994).

${ }^{20}$ D. M. King, X. Liang, and A. W. Weimer, Powder Technol. 221, 13 (2012).

${ }^{21}$ A. Goulas and J. R. van Ommen, Kona Powder Part. J. 31, 234 (2014).

${ }^{22}$ J. Lu, K.-B. Low, Y. Lei, J. A. Libera, A. Nicholls, P. C. Stair, and J. W. Elam, Nat. Commun. 5, 3264 (2014).

${ }^{23}$ T. Suntola and J. Antson, U.S. patent 4,058,430 (15 November 1977).

${ }^{24}$ W. M. M. Kessels and M. Putkonen, MRS Bull. 36, 907 (2011).

${ }^{25}$ D. H. Levy, D. Freeman, S. F. Nelson, P. J. Cowdery-Corvan, and L. M. Irving, Appl. Phys. Lett. 92, 192101 (2008).

${ }^{26}$ D. H. Levy, S. F. Nelson, and D. Freeman, J. Disp. Technol. 5, 484 (2009).

${ }^{27}$ P. Poodt, A. Lankhorst, F. Roozeboom, K. Spee, D. Maas, and A. Vermeer, Adv. Mater. 22, 3564 (2010).

${ }^{28}$ K. Lahtinen, P. Maydannik, P. Johansson, T. Kääriäinen, D. C. Cameron, and J. Kuusipalo, Surf. Coat. Technol. 205, 3916 (2011).

${ }^{29}$ T. Hirvikorpi et al., Thin Solid Films 550, 164 (2014).

${ }^{30}$ P. Poodt, D. C. Cameron, E. Dickey, S. M. George, V. Kuznetsov, G. N. Parsons, F. Roozeboom, G. Sundaram, and A. Vermeer, J. Vac. Sci. Technol., A 30, 010802 (2012).

${ }^{31}$ E. Dickey and W. A. Barrow, J. Vac. Sci. Technol., A 30, 021502 (2012).

${ }^{32}$ O. Molerus, Powder Technol. 88, 309 (1996).

${ }^{33}$ S. Friedlander and D. H. Pui, J. Nanopart. Res. 6, 313 (2004).

${ }^{34}$ C. H. Nam, R. Pfeffer, R. N. Dave, and S. Sundaresan, AIChE J. 50, 1776 (2004).

${ }^{35}$ L. F. Hakim, J. L. Portman, M. D. Kasper, and A. W. Weimer, Powder Technol. 160, 149 (2005).

${ }^{36}$ L. de Martín, A. Fabre, and J. R. van Ommen, Chem. Eng. Sci. 112, 79 (2014).

${ }^{37}$ K. L. Ostrowski, S. P. Luke, M. A. Bennett, and R. A. Williams, Chem. Eng. J. 77, 43 (2000).

${ }^{38}$ A. J. M. Mackus, D. Garcia-Alonso, H. C. M. Knoops, A. A. Bol, and W. M. M. Kessels, Chem. Mater. 25, 1769 (2013).

${ }^{39}$ J. Dendooven, R. K. Ramachandran, K. Devloo-Casier, G. Rampelberg, M. Fillez, H. Poelman, G. B. Marin, E. Fonda, and C. Detavernier, J. Phys. Chem. C 117, 20557 (2013).

${ }^{40}$ Y. Zhou, D. M. King, X. Liang, J. Li, and A. W. Weimer, Appl. Catal., B 101, 54 (2010).

${ }^{41}$ H. Feng, J. A. Libera, P. C. Stair, J. T. Miller, and J. W. Elam, ACS Catal. 1, 665 (2011). 